\title{
Floral Biology and Seed Production in Cultivated North American Ginseng (Panax quinquefolius)
}

\author{
Cayetana Schluter ${ }^{1}$ and Zamir K. Punja ${ }^{2}$ \\ Department of Biological Sciences, Center for Environmental Biology, Simon Fraser University, \\ Burnaby, British Columbia, V5A 1S6, Canada
}

\begin{abstract}
AdDitional INDEX wORDs. Flower development, pollination, seed set, berries
Aвstract. Morphological characteristics of flowers, duration of flowering, degree of self-pollination, and extent of berry and seed production in North American ginseng (Panax quinquefolius $\mathbf{L}$.) were studied under controlled environmental conditions as well as under field conditions. A comparison was also made between plants of 3 and 4 years of age at two field locations. The duration of flowering was $\approx 4$ weeks and was similar in plants of both age groups grown in the two environments; however, 4-year-old plants produced an average of $40 \%$ more flowers $(\approx 100$ per plant in total) compared to 3-year-old plants. Flowers were comprised of five greenish-colored petals, five stamens, and an inferior ovary consisting of predominantly two fused carpels and stigmatic lobes. Anthers dehisced in staggered succession within individual flowers, and flowering began with the outermost edge of the umbel and proceeded inwards. At any given time during the 4-week flowering period, $\approx 10 \%$ of the flowers in an umbel had recently opened and were producing pollen. Stigma receptivity was associated with separation of the stigmatic lobes; this occurred at some time after pollen release. Growth of pollen tubes through the style in naturally pollinated flowers was most evident when the stigmatic lobes had separated. The proportion of flowers that developed into mature berries (pollination success rate) was in the range of $41 \%$ to $68 \%$ for both 3-year-old and 4-year-old plants. However, when the inflorescence was bagged during the flowering period, berry formation was increased by $13 \%$ to $21 \%$ in 4 -year-old plants, depending on location. A majority of the berries (92\% to $99 \%$ ) contained one or two seeds in an almost equal frequency, with the remaining berries containing three seeds. In 4-year-old plants, the frequency of two-seeded berries was increased by $\approx 13 \%$ by bagging the inflorescence. These observations indicate that $P$. quinquefolius is highly self-fertile and that several physiological and environmental factors can affect seed production.
\end{abstract}

Ginseng (Panax L. sp.) is a slow-growing herbaceous perennial plant (Order Umbelliferales, Family Araliaceae) which is cultivated in many regions of the world for its highly valued root. Korean ginseng (Panax ginseng C.A. Meyer) has been used in the Orient for several thousand years for its reputed medicinal and herbal properties (Hu et al., 1980; Proctor and Bailey, 1987). North American ginseng (Panax quinquefolius L.) is native to eastern North America, and grows in regions of the northeastern states of the United States and the Canadian provinces of Quebec and Ontario (Proctor and Bailey, 1987). At present, the major regions in North America where P. quinquefolius is cultivated for commercial production are Wisconsin, and the provinces of Ontario and British Columbia, Canada (Proctor et al., 1999).

Plants are propagated sexually from stratified seed, which are planted in the fall (September to October) to give rise to first-year seedlings in the following spring (April to May). Berries containing seeds are collected when the plants are 3 to 4 years old and require a stratification period of $\approx 12$ months, during which time periods of cool and warm temperatures are provided to enhance embryo maturation (Proctor and Louttit, 1995). The berries develop on an umbel inflorescence and each contains one to two seeds or infrequently three to four seeds (Stoltz and Garland, 1980). An average of 30 to 40 berries may be produced on each

Received for publication 18 Jan. 2000. Accepted for publication 19 June 2000. Funding for this research was provided by the Natural Sciences and Engineering Research Council of Canada, Strategic Grants Program, and the Science Council of British Columbia, G.R.E.A.T. Awards program. The authors acknowledge Don McKenzie, Tom Li, Eric Littley, and Chai-Na-Ta Ginseng Farms for making available plant materials and field locations. We also thank D. Wardle, M. Van Paassen, S. Chatterton, and M. Feeney for providing assistance with the field experiments. The cost of publishing this paper was defrayed in part by the payment of page charges. Under postal regulations, this paper therefore must be hereby marked advertisement solely to indicate this fact.

${ }^{1}$ Graduate research assistant.

${ }^{2}$ Professor; to whom reprints requests should be addressed; e-mail: punja@ sfu.ca. 4-year-old plant, yielding 300 to $500 \mathrm{~kg} \cdot \mathrm{ha}^{-1}$ seed (Proctor and Bailey, 1987; Proctor et al., 1999), and the species is reported to be self-pollinated (Carpenter, 1980; Carpenter and Cottam, 1982; Lewis and Zenger, 1983; Proctor and Bailey, 1987; Schlessman, 1985). Average seed germination percentages are around $65 \%$, in part because of seed decay during stratification or embryo nonviability.

Currently, there is little published information on many aspects of the floral biology of $P$. quinquefolius A few earlier papers have described flower morphology and pollination in $P$. ginseng (Hu, 1976, 1977) or P. quinquefolius growing in the wild (Carpenter, 1980; Carpenter and Cottam, 1982; Lewis and Zenger, 1983; Schlessman, 1985). However, little has been published on aspects of flowering, pollination, and factors affecting seed production in $P$. quinquefolius plants grown under commercial conditions (McCarthy, 1996). Our objective was to examine the floral biology and factors affecting seed formation in $P$. quinquefolius plants grown under commercial conditions. This information will be relevant for studies aimed at genetic improvement of $P$. quinquefolius through selection of superior genotypes and controlled pollinations.

\section{Materials and Methods}

CONTROLLED ENVIRONMENT STUdy. Three 2-year-old and seven 3-year-old P. quinquefolius plants were obtained in June 1997 from a commercial field located near Merritt, B.C., Canada. The plants were carefully dug up and transplanted into 1-L pots containing Sunshine mix \#1 (Sun Gro Horticulture Inc., Bellevue, Wa.) and transported to the laboratory. They were placed in a controlled environment chamber set at $18{ }^{\circ} \mathrm{C}$ and with a $16-\mathrm{h}$ photoperiod provided by fluorescent lamps at an intensity of 34 $\mu \mathrm{mol} \cdot \mathrm{m}^{-2} \cdot \mathrm{s}^{-1}$ measured at canopy level with a quantum sensor (LI-185B; LI-COR, Inc., Lincoln, Neb.). The plants were watered 
every 3 to $4 \mathrm{~d}$ and fertilized once a month with $8 \mathrm{~g} \cdot \mathrm{L}^{-1}$ of a $20 \mathrm{~N}-$ 20P-20K water soluble fertilizer (Green Valley Ltd., Abbotsford, $\mathrm{BC}$, Canada). Applications of fungicide drenches at $125 \mathrm{mg} \cdot \mathrm{L}^{-1}$ (metalaxyl: methyl $N$-(2-methoxyacetyl)- $N$-(2,6-xylyl)- $D L$ alaninate; a.i. $8 \%$ and mancozeb: [[1,2-Ethanediylbis [carbamodithioato]](2-)]manganese mixture with [[1,2ethanediylbis[carbamodithioato]](2)]zinc; a.i. 64\%) were made once a week to ensure the roots remained free of disease. After 5 months of growth, the foliage naturally senesced and all plants were transferred to a $4{ }^{\circ} \mathrm{C}$ incubator and kept in the dark for 3 months. In Mar. 1998, the plants were returned to the previously described growth conditions and allowed to grow for 6 months until the foliage senesced. During this time, one application of 4 $\mathrm{g} \cdot \mathrm{L}^{-1}$ captan ( $N$-Trichloromethylmercapto-4-cyclohexene-1,2dicarboximide; a.i. 50\%) was made when Fusarium sp. was observed in some of the pots. The plants were placed back in the $4{ }^{\circ} \mathrm{C}$ incubator for 6 months and then in Feb. 1999 they were grown at ambient temperatures (range of 21 to $24^{\circ} \mathrm{C}$ ) with a 16$\mathrm{h}$ photoperiod provided by fluorescent lamps at an intensity of 40 $\mu \mathrm{mol} \cdot \mathrm{m}^{-2} \cdot \mathrm{s}^{-1}$ (measured as described previously). Foliage growth was accompanied by flower development in all plants. The stages of inflorescence development (an umbel) were monitored and individual flowers were removed and examined under a dissecting microscope to view and record the development of petals,

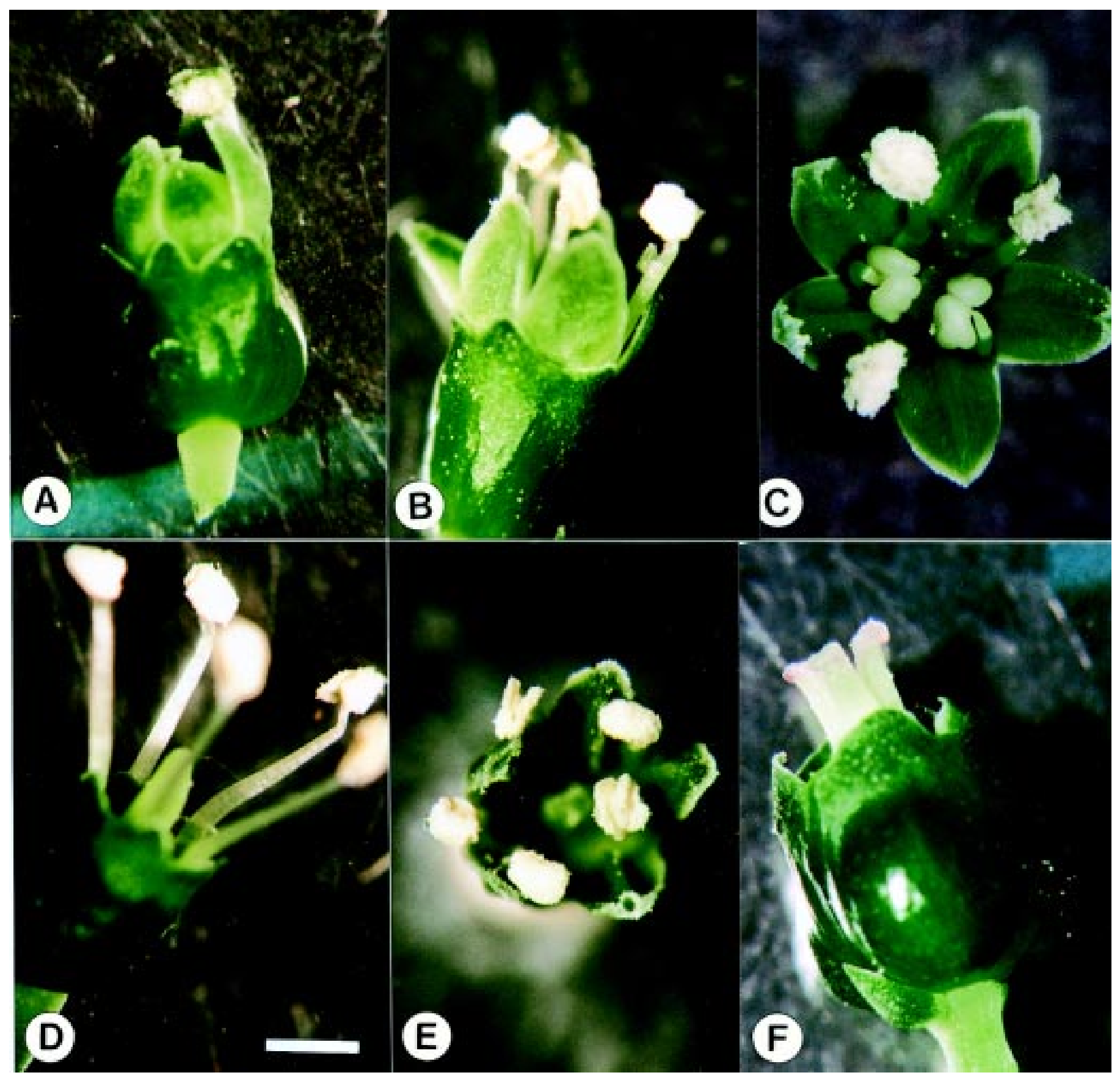

Fig. 1. Characteristics of the flowers of P. quinquefolius. (A) Mature bud at the early stages of opening, (B) flower with five light-green petals and protruding anthers, (C) fully open flower with three dehiscing anthers, and two immature anthers (top view), (D) central light-green stigma surrounded by anthers (petals were removed), (E) flower with all five anthers dehiscing (top view), and (F) fertilized flower with developing berry - note three lobes of stigma that have separated. Scale bar $=1 \mathrm{~cm}$. 
anthers, and the stigma. Production of pollen, duration of flowering, and initiation of seed set were also recorded. Samples of berries were obtained and developing seeds were sectioned and examined for embryo development.

FiELD STUdy. Two locations were selected: Summerland, B.C. $(\approx 400 \mathrm{~km}$ northeast of Vancouver at 49'35'00 latitude; 119'40'00 longitude), and Peachland (20 km east of Summerland). At each location, one field representing 3-year-old plants and one field representing 4-year-old plants were monitored starting 14 June, 1999 and ending 30 Aug. Individual healthy appearing plants (total of 14 to 16 in each age class depending on field and location) were selected, using as a criterion the presence of a well-developed umbel with none or only a few open flowers, and were tagged. On one-half of the plants, a fine-meshed white cloth

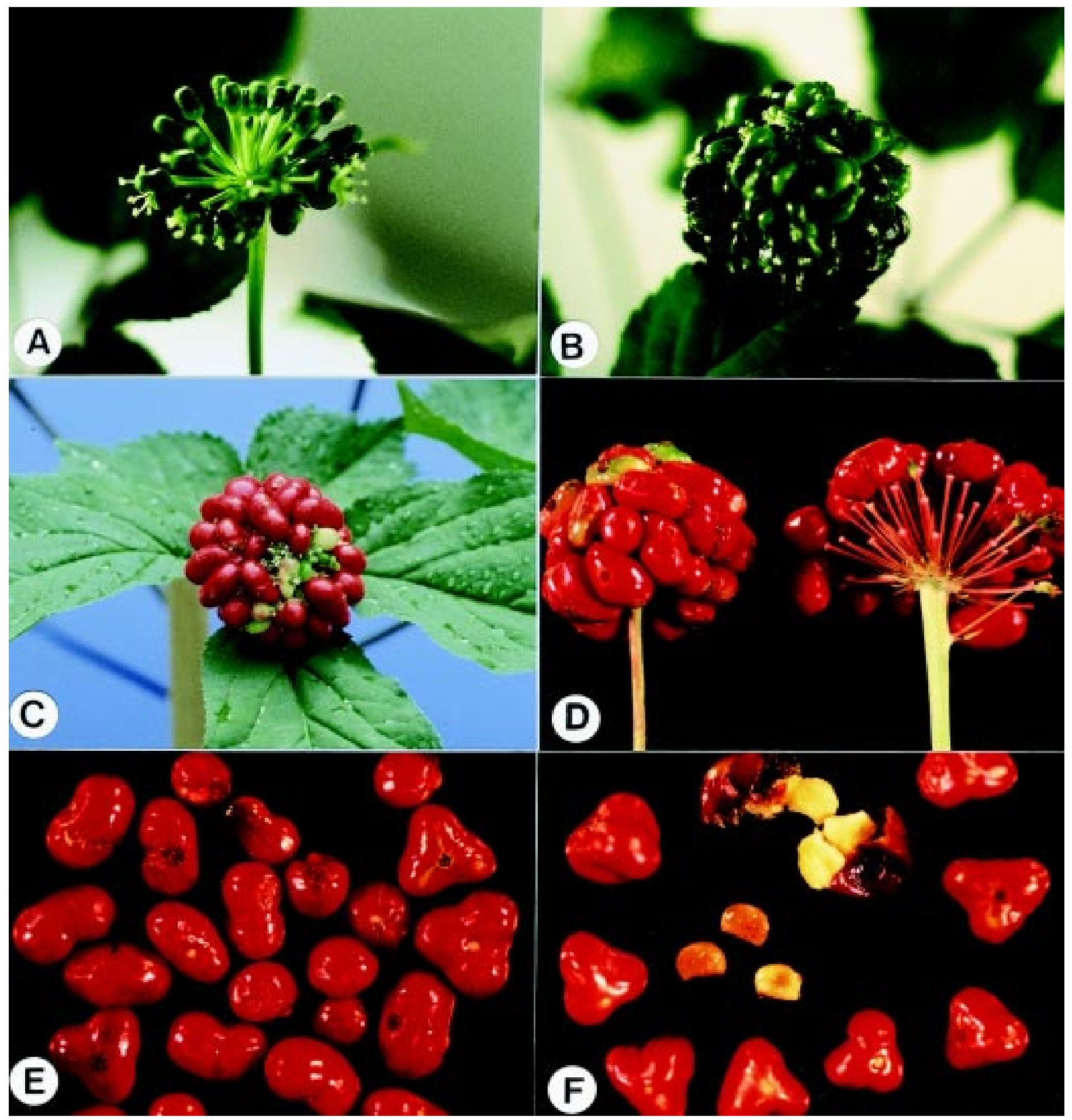

Fig. 2. Characteristics of the umbel and stages of berry development in P. quinquefolius. (A) Umbel at the early stage of flowering showing flowers opening first at the outermost edge, $(\mathbf{B})$ immature green berries on a tightly packed umbel, $(\mathbf{C})$ mature red berries with immature and underdeveloped berries in the center, (D) comparison of a fully mature umbel with dislodged berries (right) and an almost mature umbel containing a few green berries (left), (E) assortment of berries derived from one umbel (note distinct shape that corresponds to one, two, and three-seeded berries), and (F) triangular-shaped berries each with three seeds. 


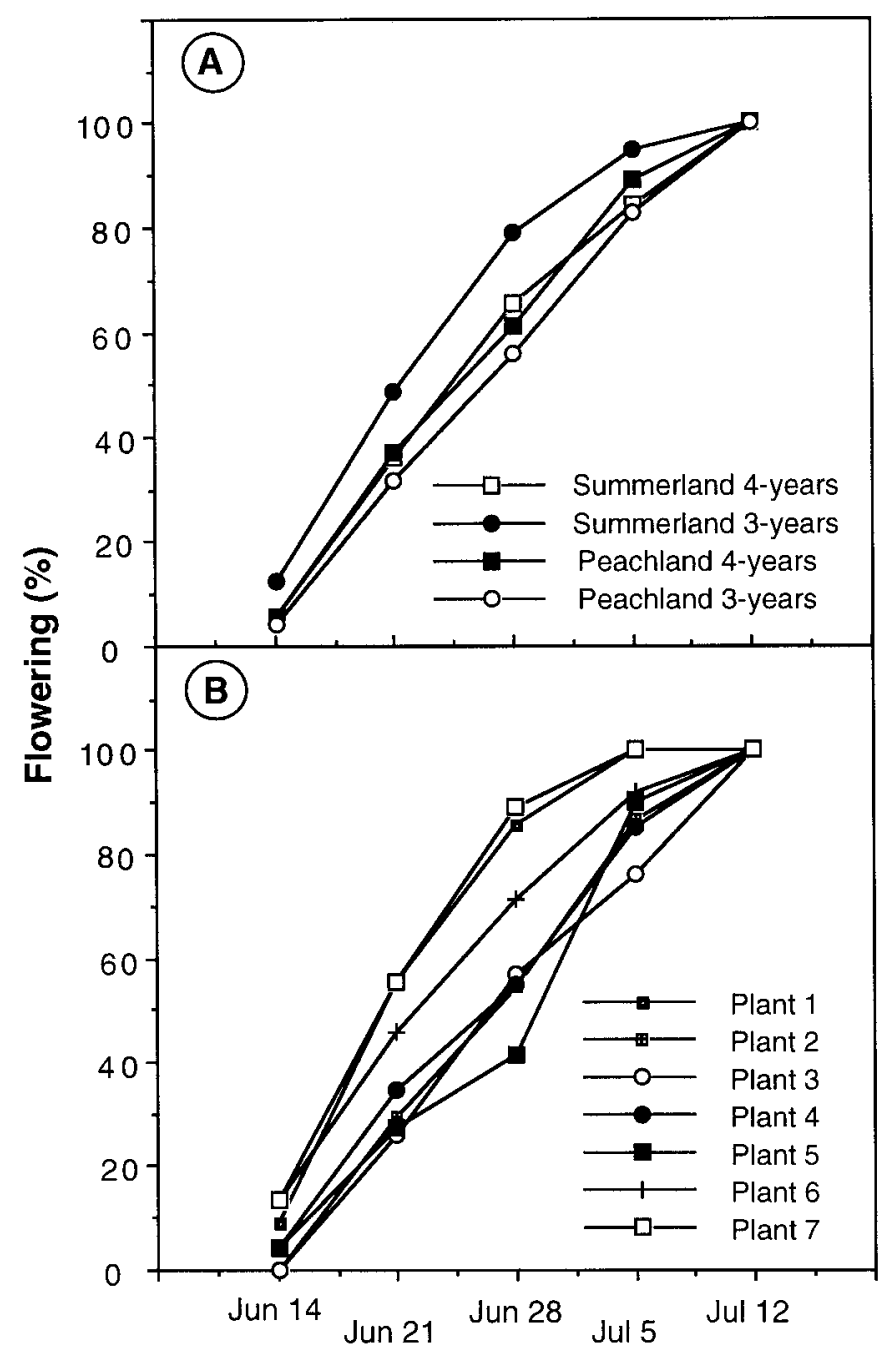

Time of sampling

Fig 3 (above). Progression of flowering in $P$. quinquefolius grown under field conditions. (A) Rates of flowering in 3-year-old and 4-year-old plants grown at two locations (Summerland and Peachland) at different sampling dates $(\mathrm{n}=8$ for each age and location), (B) variability in rates of flowering among seven 4year-old plants grown at the Peachland location.

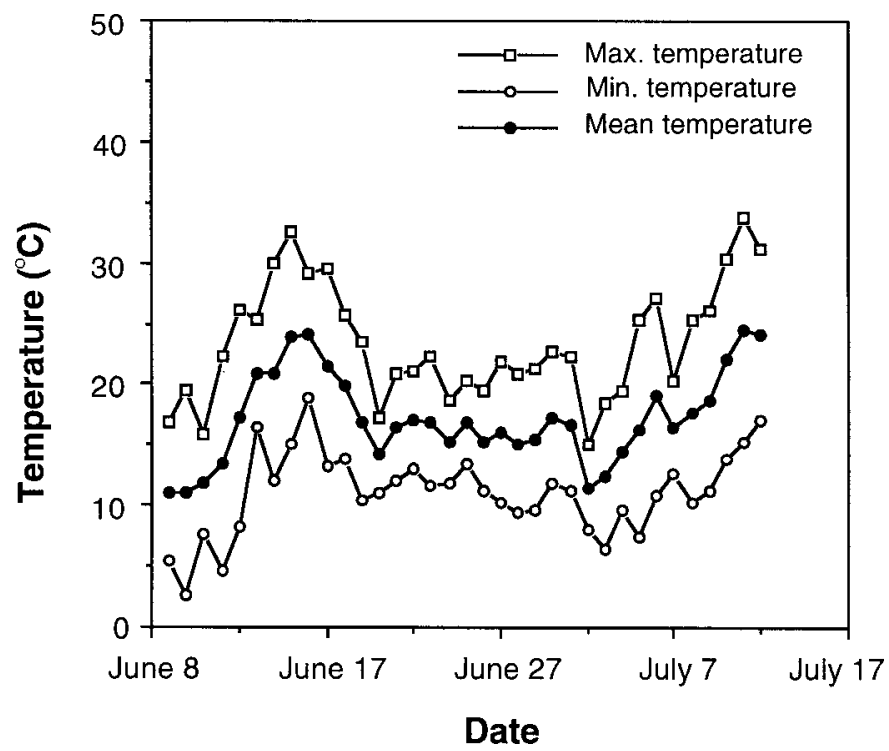

polyester bag was placed over the inflorescence and secured at the base with string; the remaining plants were left nonbagged. Before bagging, the total number of flower buds on each of the 60 plants used in the study was determined.

At weekly intervals for 5 weeks, the total number of open flowers (recently open plus previously flowered) and closed buds was counted on the nonbagged inflorescence for each of the two plant ages and two locations. In addition, visual inspection for the presence of pollen within the flowers was made. At the end of 5 weeks, the bags were removed in the bagged treatment after visually ensuring that all the buds had opened. The berries were left to develop on the plants and when ripe (red in color) were harvested from all plants 30 Aug. 1999 and transported to the laboratory. Individual berries were examined for the presence of seed by cutting them open and then they were categorized into one of four classes: no seed, or one, two or three seeds present.

Pollination in Relation to Flowering. At various times during sampling in the field study, flower buds at different stages of development (closed, partially open, and fully open) were excised from 4-year-old plants that were not among the individuals used for data collection, and the anthers were removed carefully with forceps. The flowers were transferred to vials containing formalin-glacial acetic acid-50\% ethanol (FAA) and incubated at room temperature (range of 21 to $24^{\circ} \mathrm{C}$ ) for $48 \mathrm{~h}$. The flowers were rinsed three times in distilled water and placed into $1 \mathrm{~mol} \cdot \mathrm{L}^{-1} \mathrm{NaOH}$ for $48 \mathrm{~h}$. Following this, they were rinsed three times in water and the style was cut off carefully at the base in each flower and transferred to a microscope slide. The styles were immersed in a $0.1 \%$ solution of aniline blue (Methyl blue, Sigma Chem. Co., St. Louis, Mo.) in $0.1 \mathrm{~mol} \cdot \mathrm{L}^{-1} \mathrm{~K}_{3} \mathrm{PO}_{4}$ for $20 \mathrm{~min}$ or longer (Kho and Baër, 1968) and a cover slip was gently pressed over them. The samples were viewed under ultra violet (UV) light (350 to $400 \mathrm{~nm}$ wavelength) with a compound microscope. Observations on the presence or absence of fluorescent pollen tubes within the stigmas and style were made from over 200 flowers representing the various stages of development. Photographs were taken using Fujichrome 64 tungsten type II film (Fuji Photo Film Co., Ltd., Tokyo, Japan).

Statistical Analysis. Data from selected experiments were analyzed for significant differences using one-way analysis of variance (ANOVA). Means were separated using Fisher's pairwise comparisons at $P \leq 0.05$. All tests of significance were done using Minitab 10.5 Xtra Power software (Minitab, Inc., State College, Pa.).

\section{Results}

Controlled Environment study. In all of the plants maintained under controlled conditions, flowering was initiated towards the end of Mar. 1999 and continued for a period of $\approx 4$ weeks. The flowers were small ( 2 to $3 \mathrm{~mm}$ across) and were comprised of a five-lobed calyx (Fig. 1A), five petals (Fig. 1B), five stamens (Fig. $1 \mathrm{C}, \mathrm{D}$, and E), and one to three fused carpels (Fig. 1F). Flowering began with petals opening, followed by anther dehiscence (Fig. 1A). In many of the flowers, all of the anthers did not dehisce at the same time but were staggered (Fig. 1C), while in others, anther dehiscence within a flower occurred at about the same time (Fig. 1D). At some time after the onset of anther dehiscence, the stigmatic lobes pulled apart and their tips

Fig 4. Daily maximum, minimum, and average air temperatures over the duration of the flowering period at the Summerland location. 

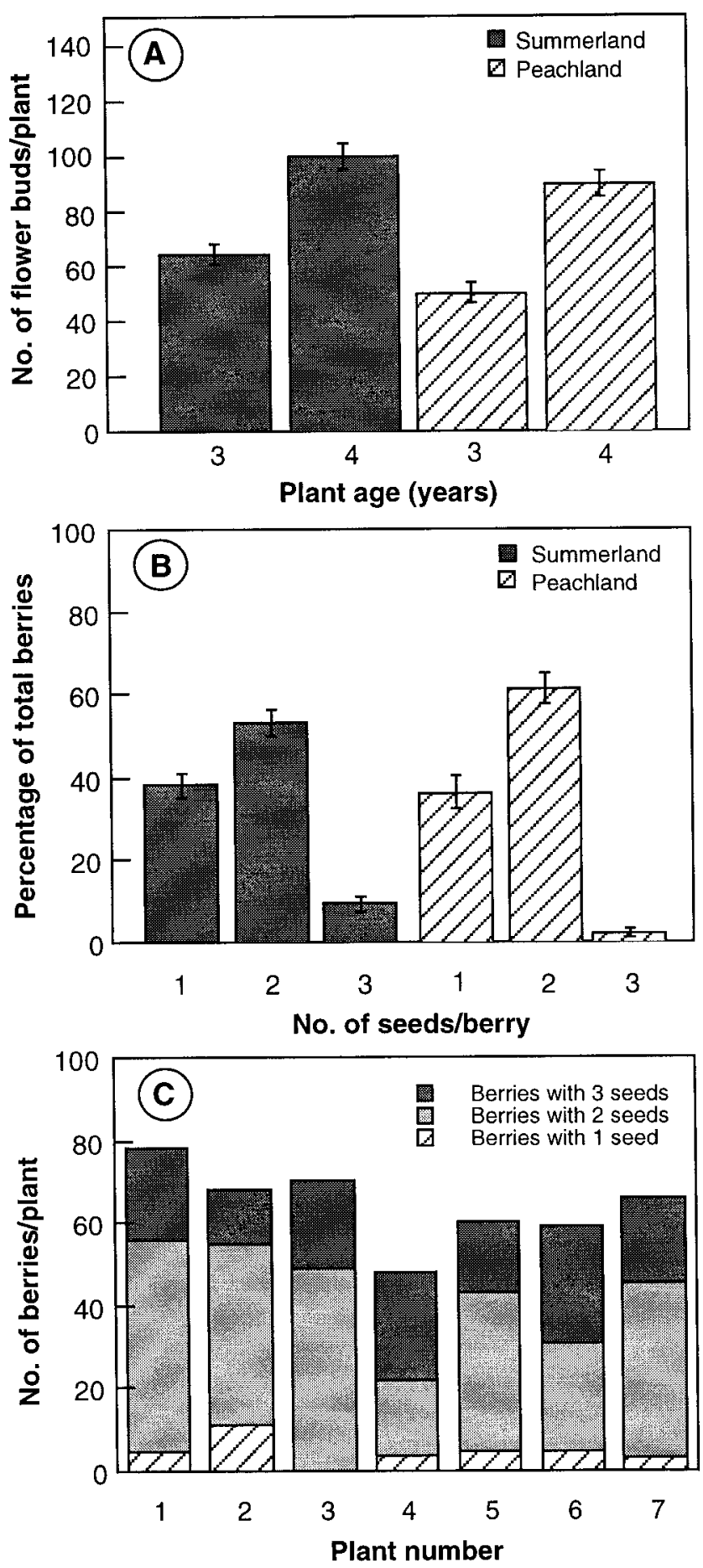

Fig. 5. (A) Average number of flower buds on 3-year-old and 4-year-old plants of $P$. quinquefolius grown at two locations (Summerland and Peachland) $(\mathrm{n}=14$ to 16 for each age class depending on location). Vertical lines represent SE. (B) Percentage of total berries which contain one, two or three seeds developing on 4-year-old plants of $P$. quinquefolius grown at two locations. Vertical lines represent SE. (C) Variability in the proportions of one-seeded, two-seeded, and three-seeded berries among seven individual 4-year-old $P$. quinquefolius plants grown at the Summerland location. Data are from plants in which the inflorescence was bagged.

extended horizontally (Fig. 1F). In all of the flowers observed, the anthers dehisced only after the stigmatic lobes had extended fully. Within an umbel, flowering began at the outermost edge and proceeded inward (Fig. 2A). Berry formation followed a similar pattern, with the youngest and least mature berries occurring in the innermost regions of the umbel (Fig. 2B and C).

Most flower buds had begun to develop berries (indicated by a visible swelling of the ovary) by the end of the flowering period of the umbel, and this occurred in the absence of insect pollinators and with minimal air circulation in the controlled environment area. Berry development occurred rapidly, reaching a diameter of 10 to $18 \mathrm{~mm}$ within $\approx 1$ week. Ripening of the berries was evident by the bright red color (Fig. 2D) and individual berries varied in size and shape (Fig. 2E). When cut open, berries were observed to contain one to three seeds (Fig. 2F).

FieLD STUDY. Flowers began to open on umbels of 3-year-old and 4-year-old plants at each of the two locations by mid-June and progressed over a 4-week period (Fig. 3A). All umbels had reached full flowering by July 12 . However, flowering rates for individual plants were variable, e.g., among 4-year-old plants in Peachland (Fig. 3B). In order to determine whether changes in ambient temperature may have been correlated with flowering rate, the average maximum/minimum air temperatures over the duration of the flowering period in the Summerland location were obtained (Fig 4). During this time, average daily temperatures in Summerland fluctuated between 11.5 to $24.2^{\circ} \mathrm{C}$ but there was no noticeable correlation with flowering rate.

Average number of flower buds per plant was significantly greater on 4-year-old plants compared to 3-year-old plants (Fig. $5 \mathrm{~A}$ ) and was not affected by location. There was significant plantto-plant variation, as indicated by the wide range in numbers of flower buds (Table 1). When open, the majority of the flowers had five anthers and two or three carpels. Occasionally, flowers with one or four carpels and rarely, with four, six or seven stamens were also observed. At any given time during the flowering period, $\approx 10 \%$ of the flowers within an umbel had opened recently and were producing pollen (data not presented).

Pollination in Relation to flowering. In closed flowers, the stigmatic lobes when viewed under the microscope were fused with each other from the base to the tip (Fig. 6A). There were no pollen grains or pollen tubes visible on these stigmas. In contrast, stigmas collected from flowers that were open partially, and some collected from fully open flowers, showed the lobes beginning to separate and germinating pollen grains were visible. In the majority of fully open flowers, the stigmatic lobes had separated and pollen grains were visible (Fig. 6B). Growth of pollen tubes down the style was clearly evident in these flowers (Fig. 6C and D) and the tubes proceeded past the point where the stigma had been excised from the flower (Fig. 6E). A closeup of the brightly fluorescent callose plugs found in pollen tubes is shown in Fig. 6F.

BERRY DEVELOPMENT. In both nonbagged and bagged inflorescences, by the end of the flowering period, berries began to develop on the umbels and were mature (red in color) by 30 Aug. 1999. The total number of ripe berries on bagged and nonbagged plants of the two ages grown at the two locations is given in Table 1. Four-yearold plants produced more berries compared to 3-year-old plants, a reflection of the higher number of flower buds. However, the pollination success rate (proportion of total flowers that developed berries) for both plant ages was comparable (in the range of $41 \%$ to $68 \%$ ) and was not affected by location. When the umbel inflorescence was bagged, there was a significant increase $(21 \%, P \leq 0.05)$ in the number of flower buds that developed into ripe berries in 4year-old plants at the Peachland location; at the Summerland location, there was also an increase in the number of ripe berries produced in bagged plants (13\%) although it was not statistically 
significant (Table 1). There was no effect of bagging on berry development on 3-year-old plants at either location. The positive effect of bagging in 4-year-old plants was translated into a higher number of total seeds per plant (Table 1). The proportion of one-, two-, and three-seeded berries produced per plant is shown in Fig. 5B. Most berries were two-seeded and there was no difference between locations. However, there was considerable plant-to-plant variation in the proportions of seeds per berry (Fig. 5C). When a comparison was made on the effect of bagging versus nonbagging on seed production, the proportion of two-seeded berries was higher (by $\approx 13 \%$ ) in bagged 4-year-old plants (data not presented).

In attempting to correlate carpel number to seed number in many of the flowers examined, it was observed that in some flowers with two or three ovules, one or more of them failed to develop into a seed. Additionally, in many flowers, the berry did not mature and aborted. The number of these aborted berries is

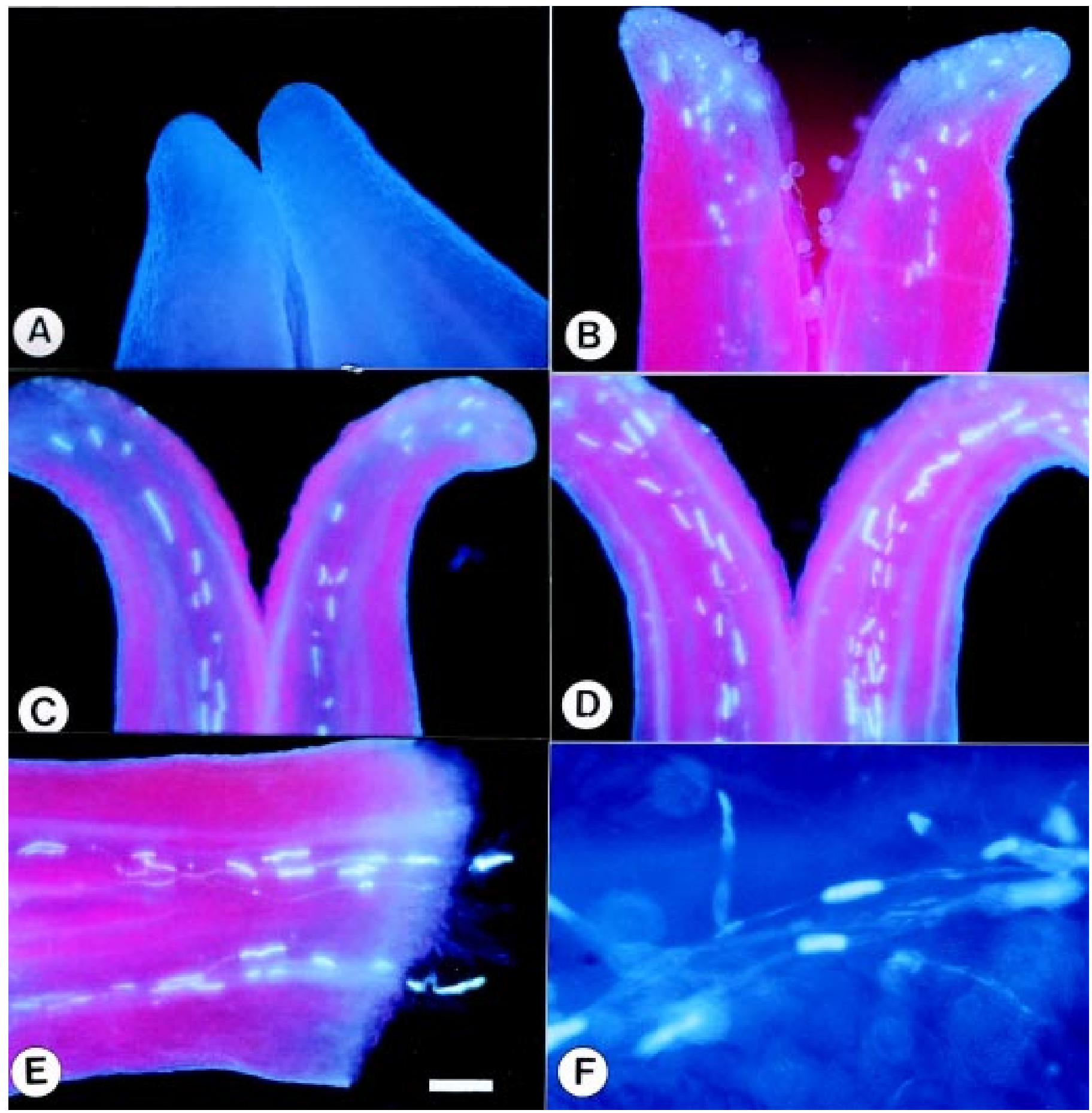

Fig. 6. Pollen tube development in stigmas and styles of $P$. quinquefolius at different stages of flower maturity. (A) Fused immature stigma with no pollen grains in a closed flower bud, (B) partially extended stigmatic surfaces with pollen grains visible and pollen tube growth in a partially open flower, (C) fully extended stigmatic lobes with pollen tubes extending into the style in a fully open flower, (D) fully extended stigmatic lobes with extensive pollen tube growth, (E) callose plugs in pollen tubes growing past the base of the excised style, and (F) closeup of two pollen tubes showing callose plugs. All photographs are of aniline-blue stained materials and were viewed under UV light with a compound microscope. In A-E the scale bar $=0.1 \mathrm{~mm}$ and in F the scale bar $=25 \mu \mathrm{m}$. 
shown in Table 1. There was a significantly lower number of aborted berries in bagged 4-year-old plants at Peachland compared to nonbagged plants. Since the stigmas were still attached to the aborted berries, pollen-tube staining was conducted as described previously to determine if pollination had taken place. It was observed that pollen tubes were present in large numbers, suggesting that postpollination events were likely responsible for berry abortion.

\section{Discussion}

There are a few previous studies that have described aspects of the floral biology in natural and cultivated populations of $P$. quinquefolius (Carpenter, 1980; Carpenter and Cottam, 1982; Lewis and Zenger, 1983; McCarthy, 1996; Schlessman, 1985). Our goal was to examine the floral biology and clarify the role played by self-compatibility in ginseng plants grown under commercial conditions. Cultivated ginseng plants differ from plants grown under natural conditions in being larger, having more leaves, producing larger roots, and having more flowers compared to noncultivated plants of the same age (Carpenter, 1980; Carpenter and Cottam, 1982; Schlessman, 1985). In general, the information available on $P$. quinquefolius flower morphology and development (Carpenter and Cottam, 1982) was supported by our observations. However, while $P$. quinquefolius flowers were reported to have five anthers originating below the stigma (Carpenter, 1980), we observed that all flowers had an inferior ovary, similar to that in $P$. ginseng flowers $(\mathrm{Hu}, 1976)$. The staggered anther dehiscence within a flower has not been reported previously.

Previous studies have suggested that $P$. quinquefolius flowers are strongly protandrous (Carpenter, 1980; Carpenter and Cottam, 1982), in that each flower contains mature anthers or pistils, but not both, and that the stigmatic lobes extended horizontally and are receptive only after the anthers had abscised. This finding was not supported by our observations, since anthers remained attached in most flowers until after the stigmatic lobes had extended fully, providing opportunities for self-pollination. Schlessman (1985) suggested that visual observation alone was inadequate to determine stigmatic receptivity. In a few pollination experiments, over $25 \%$ of the visually immature stigmas that were pollinated were receptive (Schlessman, 1985). In the present study, germinating pollen grains and pollen tubes were only observed in flowers in which the stigmatic lobes had begun to separate from one another. In some cases, flowers that appeared to be functionally male (anthers dehiscing but stigma still fused) were receptive and the stigmatic lobes had begun to separate when examined microscopically. It is possible that the visually immature but receptive stigmas observed by Schlessman (1985) had begun to separate. Our observations indicate that ginseng flowers are not as strongly protandrous as reported previously if at all. We suggest that autogamy (pollination within a flower) as well as geitonogamy (pollination between flowers on a single umbel) can both contribute to berry formation under cultivated conditions.

The $P$. quinquefolius plants included in this study were grown either in a controlled environment or at two locations in British Columbia. All plants flowered over a period of $\approx 4$ weeks, regardless of location and ambient temperature. The duration of the flowering period observed was similar to the flowering period reported previously for both cultivated and noncultivated plants. Carpenter and Cottam (1982), as well as Schlessman (1985), reported that flowering occurred within an umbel over a period of 1 to 3 weeks in noncultivated plants. Lewis and Zenger (1983) reported that flowering occurred over a period of 3 to 8 weeks for an entire population of noncultivated plants. In cultivated plants, Proctor et al. (1999) reported that flowering occurred over a 3 to

Table 1. Flower, berry, and seed production in bagged and nonbagged inflorescences of $P$. quinquefolius plants grown at two locations and representing two plant ages

Location and planting age

\begin{tabular}{|c|c|c|c|c|c|c|c|c|c|c|c|c|c|}
\hline \multirow[b]{3}{*}{ Observation } & & \multicolumn{6}{|c|}{ Summerland } & \multicolumn{6}{|c|}{ Peachland } \\
\hline & & \multicolumn{3}{|c|}{ 3-year-old $\mathrm{Z}$} & \multicolumn{3}{|c|}{ 4-year-old } & \multicolumn{3}{|c|}{ 3-year-old } & \multicolumn{3}{|c|}{ 4-year-old } \\
\hline & & Mean & Range & SE & Mean & Range & $\mathrm{SE}$ & Mean & Range & SE & Mean & Range & SE \\
\hline \multirow{2}{*}{ Total flower buds } & Bagged & 70 & $45-89$ & 5.2 & 97 & $83-127$ & 6.2 & 45 & $30-69$ & 6.0 & 91 & $65-127$ & 7.4 \\
\hline & Nonbagged & 59 & $51-77$ & 3.7 & 103 & $75-129$ & 7.3 & 55 & $48-63$ & 2.2 & 86 & $56-113$ & 6.7 \\
\hline \multirow[t]{2}{*}{ Total ripe berries } & Bagged & 31 & $23-37$ & 3.0 & 64 & $48-78$ & 3.6 & 23 & $13-34$ & 3.0 & 61 & $45-72$ & 3.3 \\
\hline & Nonbagged & 37 & $21-47$ & 4.4 & 55 & $35-89$ & 8.1 & 22 & $11-32$ & 3.4 & 40 & $14-84$ & 10.5 \\
\hline Total aborted & Bagged & 33 & $15-50$ & 9.6 & 33 & $17-49$ & 3.7 & 19 & $4-35$ & 4.8 & 32 & $12-58$ & 5.6 \\
\hline berries & Nonbagged & 20 & $13-34$ & 4.8 & 47 & $20-59$ & 10.5 & 32 & $16-52$ & 4.9 & 46 & $24-75$ & 7.0 \\
\hline \multirow[t]{2}{*}{ Total seeds } & Bagged & 47 & $30-66$ & 7.6 & 113 & 74-139 & 8.6 & 33 & $19-46$ & 4.2 & 102 & $70-126$ & 6.4 \\
\hline & Nonbagged & 55 & $31-78$ & 9.9 & 91 & $66-155$ & 14.0 & 40 & $17-91$ & 10.7 & 67 & $20-143$ & 18.1 \\
\hline
\end{tabular}

${ }^{\mathrm{Z}}$ Data presented are the means and ranges of observations from seven to eight replicate plants. 
4 week period. Flowering within an umbel began at the outermost edge and proceeded inwards, and at any given time, $\approx 10 \%$ of the flowers had opened recently and were releasing pollen. The sequential flowering characteristic of an umbel and differences in anther maturity within a ginseng flower would ensure availability of pollen for an extended time. Although generalist insect pollinators, particularly bees and ants, were observed during this study as well as in previous studies (Carpenter and Cottam, 1982; Lewis and Zenger, 1983; McCarthy, 1996), bagging of the inflorescence to exclude pollen from neighboring plants or potential pollinators either had no negative effect on berry development or enhanced development. These observations indicate that xenogamy (pollination between flowers on different umbels) may be less important for berry production in cultivated plants although it cannot be excluded, since cultivated plants are grown very close to one another and the inflorescences of neighboring plants are sometimes only several centimeters apart.

The natural fecundity of noncultivated ginseng has been reported to be low (Carpenter, 1980; Carpenter and Cottam, 1982; Lewis and Zenger, 1983; Proctor and Bailey, 1987; Schlessman, 1985 ). On average, these plants form seeds at $\approx 8$ years of age compared to 3 years when under cultivation. The average number of flowers per umbel on plants with three or four leaves when grown under natural conditions was between 9 and 27, depending on location (Schlessman, 1985). A typical, flowering 4-year-old $P$. quinquefolius plant may carry 30 to 40 berries in each inflorescence (Proctor and Bailey, 1987). In the present study, there was considerable variation from plant to plant in terms of number of flowers per umbel and rate of flowering, number of berries formed, number of aborted berries, and total number of seeds produced. Although $P$. quinquefolius has been under cultivation for more than 100 years, there are no recognized cultivars at present. Studies on intraspecific variation have shown that cultivated plants consist largely of unimproved land races and that a high degree of variation can exist (Bai et al., 1997; Boehm et al., 1999). Despite this variation, the average number of flowers per umbel recorded in the present study was 57 in 3-year-old plants and 94 in 4-yearold plants, while the average number of berries on a 4-year-old plant was 55. In noncultivated plants, the percentage of total flowers that formed fruit was $14 \%$ to $27 \%$, depending on location (Lewis and Zenger, 1983). We observed $41 \%$ to $68 \%$ of the flowers had formed fruit. These findings indicate that the fecundity of cultivated $P$. quinquefolius plants is much higher than that of noncultivated populations. This is probably because cultivated plants are grown under much more favorable conditions than in nature. Consequently, with optimal light, water, fertilization, and disease control, cultivated plants attain a larger size and can allocate more photosynthates towards flower and seed formation.

Low seed set in natural populations of $P$. quinquefolius was proposed previously to be due to inadequate pollination and/or abortion of fertilized ovules (Lewis and Zenger, 1982). In the present study, $34 \%$ to $56 \%$ of berries within an umbel failed to mature and aborted. However, this was probably not due to lack of pollen availability or low pollination since pollen tubes were observed in these berries. In general, plants can regulate investment in reproduction by varying the number of flowers produced, the relative amounts of pollen and ovules produced by individual flowers, and the number of fertilized ovules that mature into seeds (Lloyd, 1980). We observed that the number of flowers per plant and the number of fertilized ovules that matured into berries increased with the age of the plant. Previous studies showed a positive correlation between the number of flowers per plant and leaf area and plant height (Carpenter and Cottam, 1982). Proctor et al. (1999) reported that consecutive inflorescence removal for 2 years (third and fourth) increased root yields in cultivated $P$. quinquefolius by $55.6 \%$, illustrating that reproduction consumed a large amount of photosynthate. Therefore, as suggested by Schlessman (1985), female reproductive success in ginseng is probably governed by the amount of photosynthate allocated to reproduction, rather than by abundance or efficiency of pollinators.

In inflorescences that were bagged during the flowering period, berry formation and subsequent seed production were increased in 4-year-old plants. The positive effects of bagging were observed previously in some noncultivated populations of $P$. quinquefolius (Lewis and Zenger, 1983) but not in others (Carpenter, 1980; Carpenter and Cottam, 1982). Carpenter and Cottam (1982) reported that bagged plants did not differ from nonbagged plants in fruit or seed production. In contrast, Lewis and Zenger (1983) noted that there was a significant increase in the proportion of bagged flowers which formed fruit (from $14.2 \%$ in nonbagged plants to $77.8 \%$ in bagged plants) at one location but not at another. They also noted that in some populations, there was a greater number of redcolored compared to green fruits in bagged versus nonbagged umbels. They proposed that some environmental factor, such as a greater concentration of ethylene or increased temperature in bagged umbels, contributed to more rapid fruit maturation (Lewis and Zenger, 1983). In the present study, the number of ripe berries in bagged 4-year-old plants at the Peachland location increased significantly while the number of aborted berries decreased significantly as compared to nonbagged plants. Bagged 4-year-old plants at the Summerland location also had fewer berries aborted than nonbagged plants. This observation implies that in 4-year-old plants, bagging the inflorescence may have created a microclimate that reduced the number of aborted ovules by increasing either pollen germination or pollen tube growth, or enhanced the frequency of successful fertilization. Higher humidity and reduction of solar radiation inside the bags may both have contributed to this increase. Bagging had no effect on berry development in 3-year-old plants, perhaps because of limited photosynthates available to these plants to sustain more berries. This may also explain why bagging had variable effects on noncultivated plants in previous studies, since these plants tend to be smaller in size and with limited photosynthates.

During selection of traits in $P$. quinquefolius that could improve the horticultural characteristics of the crop, a bias towards larger, more vigorous plants would ensure a higher production of seed and larger roots. However, selection of umbel size with a larger number of flowers may not be desirable, since only a portion of them are able to mature into berries with seeds. Therefore, umbels in the range of 40 to 50 flowers may be the ideal carrying capacity of 4-year-old plants. In Korea, inflorescences of $P$. ginseng are thinned manually to 20 to 30 flowers and thinned further to 10 to 20 berries to enhance individual seed weight and also increase root yield ( $\mathrm{Li}, 1995)$. If self-pollinations are to be conducted to obtain true-breeding lines or recover progeny from single-seed in breeding experiments, bagging of the inflorescence is recommended to enhance seed production. If cross-pollinations are to be conducted, the delayed maturity of the stigma would be advantageous as emasculation could be conducted when the petals first open without risk of self-pollination. 


\section{Literature Cited}

Bai, D., J. Brandle, and R. Reeleder. 1997. Genetic diversity in North American ginseng (Panax quinquefolius L.) grown in Ontario detected by RAPD analysis. Genome 40:111-115.

Boehm, C.L., H.C. Harrison, G. Jung, and J. Nienhuis. 1999. Organization of American and Asian ginseng germplasm using randomly amplified polymorphic DNA (RAPD) markers. J. Amer. Soc. Hort. Sci. 124:252256.

Carpenter, S.G. 1980. Population dynamics, life history, and management recommendations for american ginseng (Panax quinquefolius L.) in Wisconsin. MS thesis, Univ. Wis., Madison.

Carpenter, S.G. and G. Cottam. 1982. Growth and reproduction of american ginseng (Panaxquinquefolius) in Wisconsin, U.S.A.Can. J. Bot. 60:26922696.

Hu, S.Y. 1976. The genus Panax (ginseng) in Chinese medicine. Econ. Bot. 30:11-28.

Hu, S.Y. 1977. A contribution to our knowledge of ginseng. Amer. J. Chinese Med. 5:1-23.

Hu, S.Y., L. Rüdenberg, and P. Del Tredici. 1980. Studies of American ginsengs. Rhodora 82:627-636.

Kho, Y.O. and J. Baër. 1968. Observing pollen tubes by means of fluorescence. Euphytica 17:298-302.

Lewis, W.H. and V. Zenger. 1982. Population dynamics of the American ginseng Panax quinquefolium (Araliaceae). Amer. J. Bot. 69:1483-
1490.

Lewis, W.H. and V.Zenger. 1983. Breeding systems and fecundity in the American ginseng, Panax quinquefolium (Araliaceae). Amer. J. Bot. 703:466-468.

Li, T.S.C., 1995. Asian and American ginseng-A review. HortTechnology 5:27-34.

Lloyd, D.G. 1980. Sexual strategies in plants. I. An hypothesis of serial adjustment of maternal investment during one reproductive session. New Phytol. 86:69-79.

McCarthy, J.A. 1996. The effects of insect pollination on the seed set and seed viability of American ginseng (Panax quinquefolium L.). MS thesis, Univ. of Guelph, Guelph, Ontario, Canada.

Proctor, J.T.A. and W.G. Bailey. 1987. Ginseng: Industry, botany, and culture. Hort. Rev. 9:187-236.

Proctor, J.T.A. and D. Louttit. 1995. Stratification of american ginseng seed: Embryo growth and temperature. Korean J. Ginseng Sci. 19:171174

Proctor, J.T.A., D.C. Percival, and D. Louttit. 1999. Inflorescence removal affects root yields of american ginseng. HortScience 34:8284.

Schlessman, M.A. 1985. Floral biology of American ginseng (Panax quinquefolium). Bul. Torrey Bot. Club 112:129-133.

Stoltz, L.P. and P. Garland. 1980. Embryo development of ginseng seed at various stratification temperatures. Proc. 2nd Natl. Ginseng Conf. Missouri Dept. of Conservation, Jefferson City. p. 43-51. 